[Agr. Biol. Chem., Vol. 34, No. 2, p. 325 326, 1970]

\title{
Structure of Xanthocidin
}

Sir:

We wish to propose the structure (I), 4,5dihydroxy-5-isopropyl-4-methyl-2-methylene-3oxocyclopentanecarboxylic acid, for xanthocidin, the antibiotic isolated in our laboratory.

Xanthocidin (I), $\mathrm{C}_{11} \mathrm{H}_{16} \mathrm{O}_{5},{ }^{1 \prime} \mathrm{mp} 185^{\circ} \mathrm{C}$ (dec.), $[\alpha]_{\mathrm{D}}^{25}+16.7$, is an acidic compound ( $\left.\mathrm{p} K^{\prime} \mathrm{a}, 3.8\right)$ and soluble in lower alcohols, esters and ketones. It is, however, slightly soluble in chloroform and water, and insoluble in benzene. Xanthocidin (I) shows $\lambda_{\max }^{\mathrm{MeOH}} 227 \mathrm{~m} \mu$ $(\varepsilon, 6420$; cyclopentanone conjugated with exocyclic methylene) ${ }^{2 a)}$ and infrared peaks (nujol) at $3480(\mathrm{OH}), 1733$ (conjugated cyclopentanone), $1714(\mathrm{COOH}$, it shifts to 1580 $\mathrm{cm}^{-1}$ by the formation of $\mathrm{Rb}$ salt), 1635 $\mathrm{cm}^{-1}$ (double bond).
The NMR spectrum of xanthocidin (I) is most informative, as represented in Fig. 1. The equivalent two-methyl protons of isopropyl group ${ }^{31}$ appear as a doublet $(J=6.9 \mathrm{~Hz})$ at $\delta 1.15$, which is collapsed to a singlet by the irradiation of isopropyl-methine proton multiplet centered at $\delta 2.43$. The irradiation of isopropyl-methyl protons collapses the methine proton multiplet to a singlet. In addition, the long-range couplings between $\mathrm{H}(1)$ and $\mathrm{H}(2 \mathrm{a})(J=2.1 \mathrm{~Hz})$ and between $\mathrm{H}(\mathrm{l})$ and $\mathrm{H}(2 \mathrm{~b})(J=1.8 \mathrm{~Hz})$ have been confirmed by decoupling experiments.

I on hydrogenation with $\mathrm{Pd} / \mathrm{C}$ consumed one mole-equivalent of hydrogen to give colorless crystalline dihydroxanthocidin (II), ${ }^{*}$ $\mathrm{C}_{11} \mathrm{H}_{18} \mathrm{O}_{5}$ (Anal. Found: C, 57.44; $\mathrm{H}, 7.62$ ).

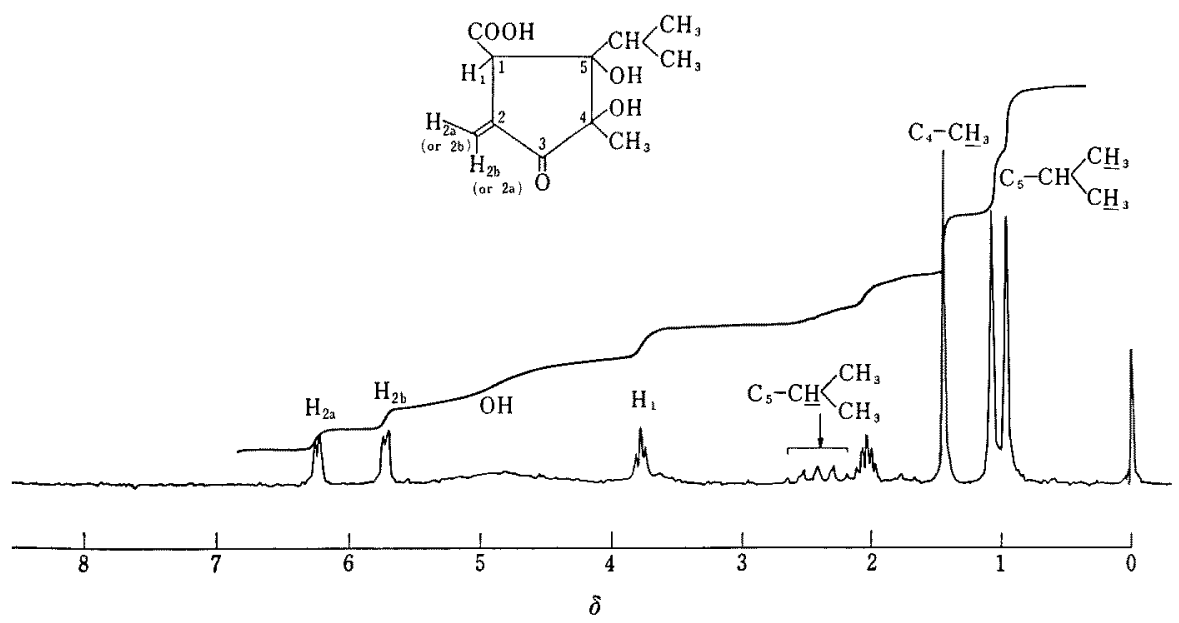

FIG. 1. NMR Spectrum of Xanthocidin $\left(\left(\mathrm{CD}_{3}\right)_{2} \mathrm{CO}\right)$.

1) K. Asahi, J. Nagatsu and S. Suzuki, J. Antibiotics, A19, 195 (1966).

2) (a) A. I. Scott, "Interpretation of the Ultraviolet Spectra of Natural Products,'” Pergamon Press, London, 1964 , p. 67. (b) ibid., pp. 29 and 33.

3) The facile loss of 61 mass units from the mole- cular ion $\left(\mathrm{M}-\mathrm{H}_{2} \mathrm{O}-\mathrm{C}_{3} \mathrm{H}_{7}\right)$ also indicates the presence of an isopropyl substituent.

* NMR data show that II is an almost equimolar crystal mixture of diastereomers due to $\alpha$ - and $\beta$ methyl group formed by the reduction. 


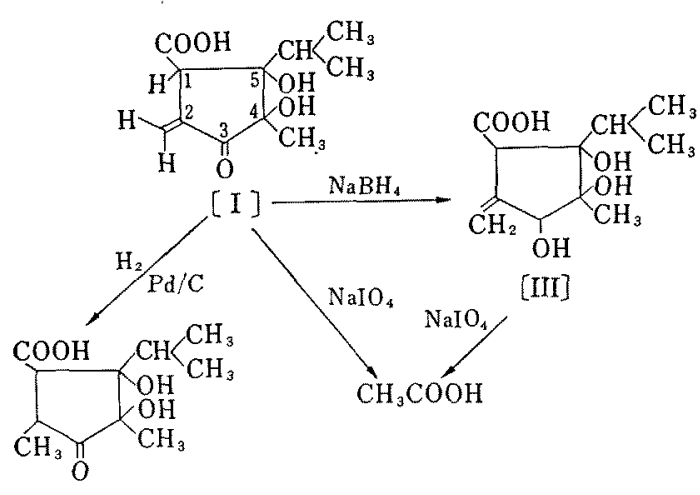

SCHEME $I$.

The structure of II is supported by the facts: (a) The UV spectrum is similar to that of unconjugated cyclopentanone ${ }^{2 b)}\left[\lambda_{\max }^{\mathrm{MeOH}} 295 \mathrm{~m} \mu\right.$ $(\epsilon, 36)]$. (b) In the IR spectrum, $\nu_{c=c} 1635 \mathrm{~cm}^{-1}$ disappears and shift of $\nu_{\mathrm{c}=0}$ is observed (to $1760 \mathrm{~cm}^{-1}$ ). (c) The NMR spectrum shows that II has no olefinic proton and $\mathrm{C}-\mathrm{CH}_{3}$ was formed (centered at $\delta$ 1.05).

According to NMR data, the carbon atom which has methyl or isopropyl group contains no proton. Therefore methyl (isopropyl) group must attach to $\mathrm{C}_{4}\left(\mathrm{C}_{5}\right)$ or $\mathrm{C}_{5}\left(\mathrm{C}_{4}\right)$. If methyl (isopropyl) attaches to $\mathrm{C}_{4}$, oxidation of $\mathrm{I}$ or reduced trioxyderivative (III) with $\mathrm{NaIO}_{4}$ would give acetic acid (isobutyric acid). I was reduced by $\mathrm{NaBH}_{4}$ in ethanol to afford colorless needles (III), $\mathrm{C}_{11} \mathrm{H}_{18} \mathrm{O}_{5}$, mp $184^{\circ} \mathrm{C}$. (Anal. Found: C, 57.04; H, 8.17. The UV absorption of conjugated cyclopentanone and $\nu_{c=0} 1733 \mathrm{~cm}^{-1}$ in the IR spectrum disappeared). III was oxidized with $\mathrm{NaIO}_{4}$ to give acetic acid ( 0.7 mole per mole of I). Prolonged treatment of $\mathrm{I}$ with $\mathrm{NaIO}_{4}$ (4 days) also gave acetic acid ( 0.8 mole-equivalent) (Scheme I). $p$-Bromophenacylester of acetic acid was identified by comparison of its mass spectrum, TLC, and retention times on two different columns (VPC) with those of an authentic sample.

These results are consistent with the structure I of xanthocidin.

We wish to thank Dr. Y. Sumiki, Vice President of this institute, for his encouragement throughout this work, and Dr. N. Ikekawa, Tokyo Institute of Technology, for conducting the VPC comparison.

Ken-ichi AsaHI Saburo SUZUKI

The Institute of Physical and Chemical Research, Yamato-machi, Saitama

Received December 5, 1969 